\title{
Necrolytic acral erythema in a Chinese patient with hepatitis $C$ and hepatitis B virus coinfection*
}

\author{
Ruzeng $X^{1} e^{1}$, Amira Elbendary ${ }^{2}$, Tieqiang $\mathrm{Wu}^{1}$
}

DOI: http://dx.doi.org/10.1590/abd1806-4841.20197257

\begin{abstract}
Necrolytic acral erythema is a distinct erythema that has been described as an extrahepatic manifestation of hepatitis $C$ virus infection. Most reported cases have been in Africa, especially Egypt. We report the first case (to the best of our knowledge) of necrolytic acral erythema in a Chinese patient with HCV and HBV coinfection. We aim to increase awareness for recognizing this condition in the Chinese population.
\end{abstract}

Keywords: Hepatitis B; Hepatitis C; Necrolytic migratory erythema

\section{INTRODUCTION}

Necrolytic acral erythema (NAE) is a distinct form of necrolytic erythema that has been reported as a cutaneous marker for hepatitis C virus (HCV) infection. NAE was first described in 1996 in a series of seven patients with HCV infection in Egypt, and since then numerous cases of necrolytic acral erythema have been reported worldwide, mostly in Africa, especially Egypt. ${ }^{1}$ To the best of our knowledge, we report the first case in the English and Chinese literature of necrolytic acral erythema in a mainland Chinese patient with $\mathrm{HCV}$ and hepatitis B virus (HBV) coinfection.

\section{CASE REPORT}

A 35-year-old Chinese man was evaluated for scaly erythematous plaques on both hands and feet associated with pruritus, with one-year duration. The patient's medical history included HCV and HBV infection for ten years with no history of antiviral treatment. The case was diagnosed as psoriasis and treated with topical clobetasone cream for 3 months without improvement, then interrupted. Physical examination showed sharply demarcated erythematous to violaceous hyperkeratotic scaly plaques symmetrically dis- tributed on the dorsal aspect of hands, fingers, feet, toes, and right ankle. Auspitz sign was negative. Erosion and fissures were noted on the surface of some lesions (Figure 1). There was no extension of the lesions to palms and soles. Examination of the nails revealed no abnormalities, and no other body parts were affected. Patient's liver function tests included alanine aminotransferase (ALT) 45U/L (normal 5-50U/L) and aspartate aminotransferase (AST) 62U/L (normal 5-40U/L). Tests for hepatitis B surface antigen (HBsAg), hepatitis B envelope antigen (HBeAg), and anti-hepatitis B core antibody (Anti-HBc) were all positive. Serum HCV antibody was positive. HCV ribonucleic acid (RNA) was $3.22 \times 10^{5} \mathrm{IU} / \mathrm{ml}$. Skin biopsy from the lesion on the right ankle was taken. Histopathological examination revealed psoriasiform epidermal hyperplasia, focal epidermal pallor, and spongiosis with scattered dyskeratotic keratinocytes. Interface change and dense band-like lymphocytic infiltration mixed with eosinophils were noted (Figure 2). Based on the histopathological features, with the consistent acral distribution of the lesions, and a background of HCV infection, the case was diagnosed as necrolytic acral erythema (NAE). Zinc level and therapeutic supplementation

Received 05 May 2017.

Accepted 02 February 2018.

* Study conducted at the Dermatology Hospital of Southern Medical University, Guangdong Provincial Dermatology Hospital, Guangzhou, China. Financial support: None.

Conflict of interest: None.

1 Department of Dermatology, Dermatology Hospital of Southern Medical University, Guangdong Provincial Dermatology Hospital, Guangzhou, China. Department of Dermatology, Kasralainy Faculty of Medicine, Cairo University, Cairo, Egypt.

\section{MAILING AdDRESS:}

Tieqiang $\mathrm{Wu}$

E-mail:tq_wu@163.com 


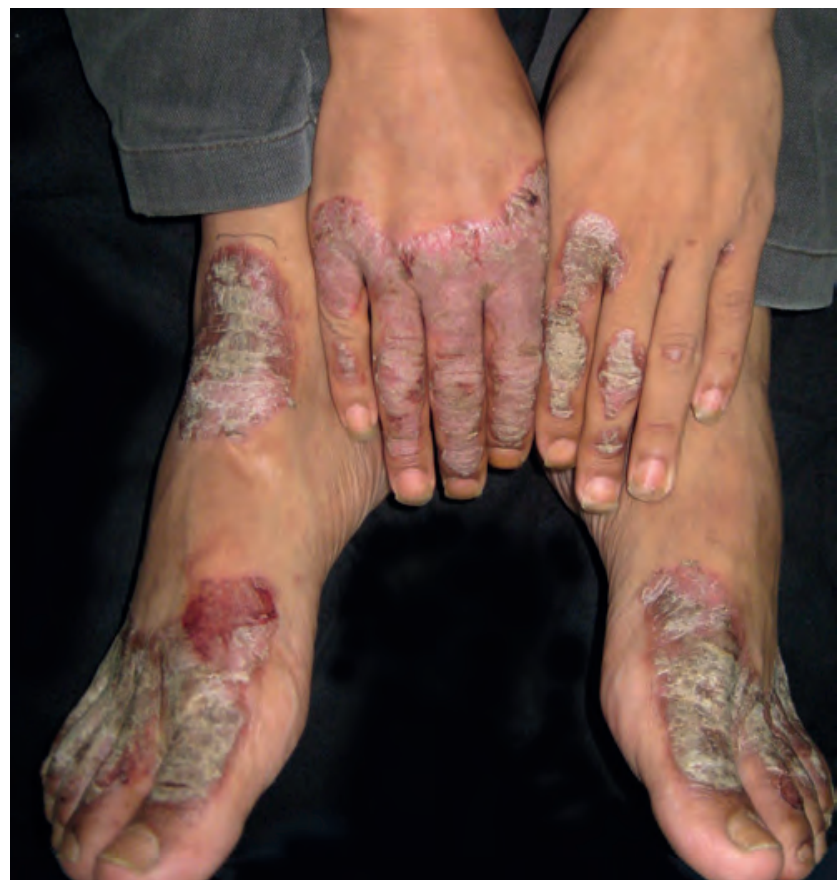

FIGURE 1: Well-demarcated hyperkeratotic erythematous to violaceous scaly plaques symmetrically involving both the dorsal surface of hands and feet, predominantly on the fingers and toes. Erosion and fissures noted on the surface

were planned accordingly, but patient was lost to follow-up with no information about treatment and prognosis.

\section{DISCUSSION}

An estimated 3\% of the world's population is HCV-infected, with the highest prevalence in Egypt (15\% to $20 \%$ ), where the majority of cases with NAE have been reported. ${ }^{2}$ In China, an updated national survey in 2006 showed that the anti-HCV prevalence rate was $0.43 \%$ in the general population, but NAE prevalence among $\mathrm{HCV}$-positive patients remains undetermined. ${ }^{3}$

Necrolytic acral erythema is one of the necrolytic erythemas, which include necrolytic migratory erythema (NME), acrodermatitis enteropathica, and various dermopathies secondary to nutritional deficiencies. NAE is distinct from the other necrolytic erythemas by virtue of its consistent association with hepatitis $\mathrm{C}(\mathrm{HCV})$ together with the acral distribution of its lesions. ${ }^{4}$ Acute lesions of NAE present as erythematous papules and blisters that eventually lead to dark red erosions with a characteristic acral distribution. As for established lesions, sharply defined hyperkeratotic erythematous to violaceous plaques develop, and crusts may be seen. ${ }^{5}$ Patients may report associated itching, burning, or aching pain in the lesions. NAE may mimic psoriasis, pellagra, or chronic eczema, but its characteristic histopathological features that demonstrate psoriasiform epidermal hyperplasia and superficial necrotic keratinocytes that vary according to the chronicity of the lesions, on a background of a distinct acral distribution without nail involvement, help in preventing misdiagnosis. ${ }^{6}$ The pathogenesis of NAE is unclear. Hepatocellular dysfunction and low serum levels of amino acids, gluca-
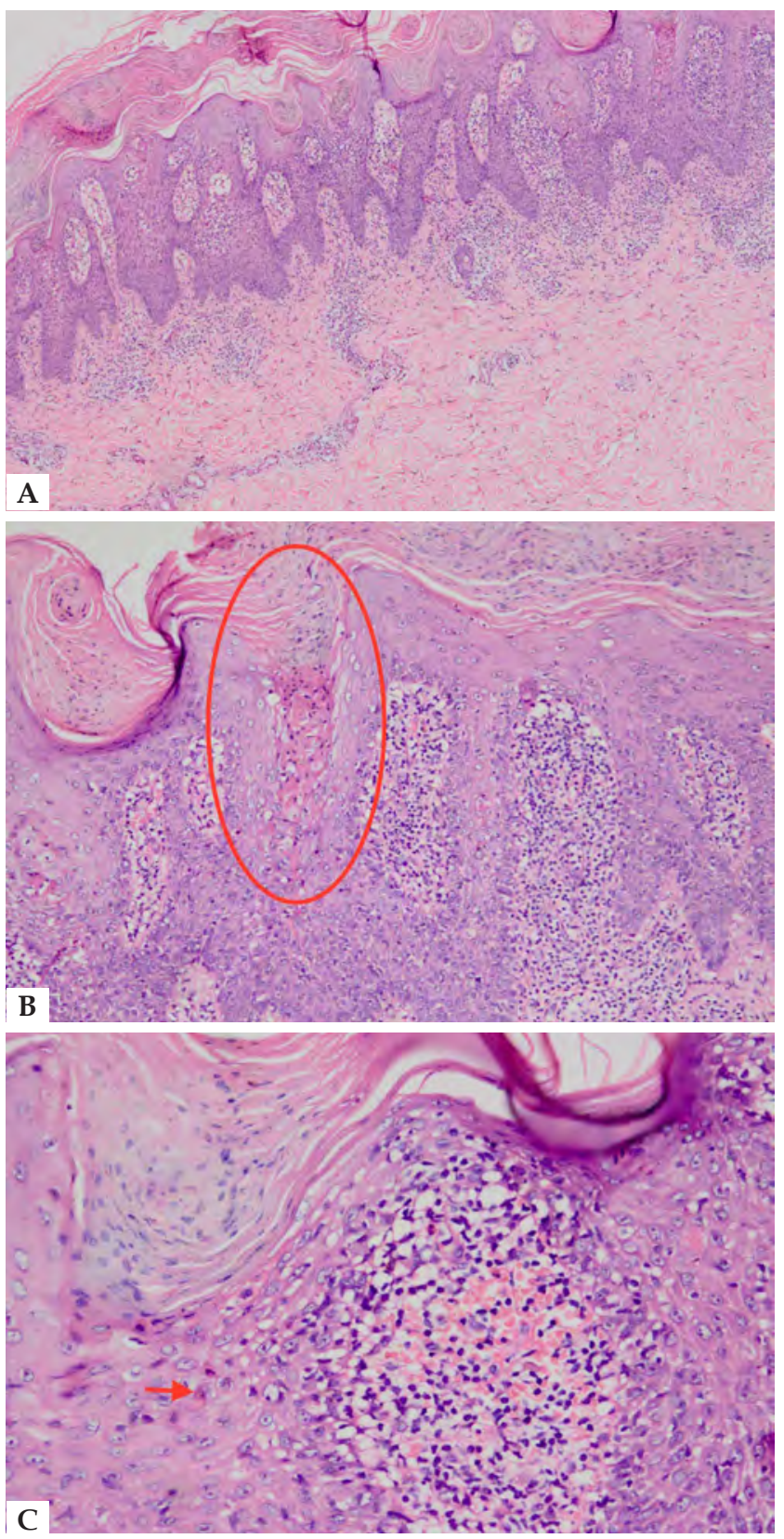

FIGURE 2: A - Hyperkeratosis, parakeratosis, psoriasiform epidermal hyperplasia with areas of spongiosis, lichenoid interface change (Hematoxylin \& eosin, original magnification $\mathrm{x} 40$ ); B: Hyperkeratosis, parakeratosis, psoriasiform epidermal hyperplasia with areas of spongiosis, lichenoid interface change (Hematoxylin \& eosin, original magnification $x 40$ ) C: Higher magnification showing parakeratosis, scattered necrotic keratinocytes, and lymphocytic infiltration admixed with eosinophils (Hematoxylin \& eosin, original magnification x200)

gon, and albumin that are associated with chronic HCV infection are proposed as playing a role in the development of the disease .?

Our case increases the awareness of its possible occurrence in $\mathrm{HCV}$-positive patients in the Chinese population and highlights the importance of early recognition to allow effective treatment and prevent misdiagnosis. $\square$ 


\section{REFERENCES}

1. el Darouti M, Abu el Ela M. Necrolytic acral erythema: a cutaneous marker of viral hepatitis C. Int J Dermatol. 1996;35:252-6.

2. Hepatitis C: global prevalence. Wkly Epidemiol Rec. 1997;72:341-4.

3. Cui Y, Jia J. Update on epidemiology of hepatitis B and C in China. J Gastroenterol Hepatol. 2013;28:7-10.

4. Tabibian JH, Gerstenblith MR, Tedford RJ, Junkins-Hopkins JM, Abuav R. Necrolytic acral erythema as a cutaneous marker of hepatitis C: report of two cases and review. Dig Dis Sci. 2010;55:2735-43.

5. El-Ghandour TM, Sakr MA, El-Sebai H, El-Gammal TF, El-Sayed MH. Necrolytic acral erythema in Egyptian patients with hepatitis $C$ virus infection. J Gastroenterol Hepatol. 2006;21:1200-6.
6. Abdallah MA, Ghozzi MY, Monib HA, Hafez AM, Hiatt KM, Smoller $B R$, et al. Necrolytic acral erythema: a cutaneous sign of hepatitis $C$ virus infection. J Am Acad Dermatol. 2005;53:247-51.

7. Nofal AA, Nofal E, Attwa E, El-Assar O, Assaf M. Necrolytic acral erythema: a variant of necrolytic migratory erythema or a distinct entity? Int J Dermatol. 2005;44:916-21.

\section{AUTHORS CONTRIBUTIONS}

$\begin{array}{lll}\text { Ruzeng Xue } & \text { (D) ORCID 0000-0002-7917-7356 }\end{array}$

Conception and planning of the study.

Amira Elbendary

(D) ORCID

0000-0001-5003-0994

Approval of the final version of the manuscript; Elaboration and writing of the manuscript; Critical review of the literature.
(19) ORCID 2 -0000-0002-9103-4817

Approval of the final version of the manuscript; Conception and planning of the study; Elaboration and writing of the manuscript; Obtaining, analyzing and interpreting the data; Effective participation in research orientation; Intellectual participation in propaedeutic and/or therapeutic conduct of the cases studied; Critical review of the literature; Critical review of the manuscript.

How to cite this article: Xue R, Elbendary A, Wu T. Necrolytic acral erythema in a Chinese patient with hepatitis C and hepatitis B coinfection. An Bras Dermatol. 2019;94(4):446-8. 